\title{
AÇÕES CULTURAIS DE FOMENTO A LEITURA EM BIBLIOTECAS ESCOLARES
}

\author{
Ana Carolina Cardoso \\ Bibliotecária - Colégio Pedro II \\ anaccardoso@cp2.g12.br
}

Resumo

\begin{abstract}
Destaca a missão da biblioteca escolar e elucida que ela deve ser dinâmica e se desenvolver pensando na formação de leitores, no que diz respeito ao espaço, acervo e serviços. Afirma que o bibliotecário deve ser um agente dinamizador da leitura, transpondo sua função técnica para disseminar a informação. Indica a função cultural da biblioteca escolar para a organização de eventos de fomento à leitura em seu espaço. Apresenta ações culturais na prática, com o objetivo de atrair o interesse do público infantil para a biblioteca e para as obras literárias, incentivando a leitura.
\end{abstract}

Palavras-chave: Biblioteca escolar. Ação cultural. Mediação. Leitura. Formação do leitor.

\section{INTRODUÇÃO}

$\mathrm{O}$ incentivo à leitura nas primeiras séries do ensino fundamental é de grande valor para o desenvolvimento literário e de aprendizado das crianças que estão nessa fase. No processo de alfabetização dos alunos deve haver uma preocupação para que, além de aprenderem a ler e escrever, eles possam ser introduzidos no mundo da leitura. Nesse contexto de letramento, o uso da biblioteca é essencial para despertar o desejo e o incentivo à leitura. Para que possa assumir seu lugar na escola como mediadora da leitura, a biblioteca escolar deve realizar ações de dinamização do seu espaço com a intenção de valorizá-lo.

Tendo em vista estimular o uso da biblioteca pelos alunos e levando em consideração a relevância do incentivo à leitura e a preocupação em mostrar diferentes obras de interesse às crianças, a Biblioteca do campus Humaitá I do Colégio Pedro II promoveu o Encontro Literário em Junho de 2016. O evento, feito em parceria com as Coordenações de Literatura e Língua Portuguesa do campus, foi dividido em vários momentos que aconteciam simultaneamente, possibilitando que os alunos e os responsáveis participassem de todas as dinâmicas propostas. O chamariz principal do evento era o troca-troca de livros, cuja proposta era focada em impulsionar o uso dos livros mostrando os gêneros distintos que cada um se interessa a ler.

O objetivo deste trabalho é descrever o processo de desenvolvimento das ações planejadas pela biblioteca, ratificar a importância das bibliotecas escolares para a construção de leitores e indicar ações que podem ser realizadas pelas bibliotecas para promover seu espaço e fomentar a leitura.

\section{MARCO TEÓRICO}

É indiscutível a importância que a leitura tem no que diz respeito à capacitação do conhecimento e uso da informação. É a biblioteca escolar quem faz surgir no aluno a vontade de descobrir mais nos livros e o faz voltar com um interesse ainda maior. Ela promove serviços que apoiam a prática pedagógica e disponibiliza os livros à comunidade escolar. Por isso, a missão da biblioteca também está vinculada à escola. Conforme dito por Côrte e Bandeira:

\footnotetext{
A biblioteca escolar é um espaço de estudo e construção do conhecimento, coopera com a dinâmica da escola, desperta o interesse intelectual, favorece o enriquecimento cultural e incentiva a formação do hábito de leitura. Jamais será uma instituição independente, porque sua atuação reflete as diretrizes de outra instituição que é a escola. Essa situação de dependência faz com que a biblioteca, para cumprir o seu papel, esteja em estreita sintonia com a concepção
} 


\section{Anais do Encontro Paraibano de Biblioteca Escolar}

educacional e as diretrizes políticopedagógicas da escola à qual se integra (CÔRTE; BANDEIRA, 2011, p.8)

A biblioteca escolar tem a importante missão de auxiliar no processo de ensinoaprendizagem como instrumento integrado, oferecendo aos seus alunos serviços de informação que complementem a prática pedagógica. É pensando na construção intelectual do aluno que a biblioteca se desenvolve, levando-o em consideração no que diz respeito ao espaço, acervo e serviços. Caldin (2003, p.163) destaca que "[...] além de despertar o gosto pela leitura como forma habitual de lazer, um dos objetivos da biblioteca escolar é a formação do cidadão consciente e capaz de um pensamento crítico e criativo". A partir disso, o aluno pode se tornar um leitor crítico e questionador, sabendo usar a informação que lhe é oferecida em vários formatos e meios.

A missão da biblioteca dentro da escola também é destacada pela IFLA ${ }^{1}$. De acordo com The IFLA/UNESCO School Library Guidelines ${ }^{2}$ :

A biblioteca escolar propicia informação e ideias que são fundamentais para o sucesso de seu funcionamento na sociedade atual, cada vez mais baseada na informação e no conhecimento. A biblioteca escolar habilita os alunos para a aprendizagem ao longo da vida e desenvolve sua imaginação, preparando-os para viver como cidadãos responsáveis (THE IFLA/UNESCO, 2005, p.4)

Para que a biblioteca possa sensibilizar o público infantil e juvenil e atraí-lo para seu espaço, é necessário pensar no papel do bibliotecário como agente dinamizador. Ele deve apresentar ao público os recursos disponíveis na biblioteca e desenvolver ações de promoção da leitura e da pesquisa, envolvendo os alunos a retornarem sempre. A biblioteca escolar que quer ser vista como

1 IFLA - International Federation of Library Associations and Institutions (Federação Internacional de Associações de Bibliotecários e Instituições)

${ }^{2}$ Diretrizes da IFLA/ UNESCO para a biblioteca escolar (2005) centro dinamizador da leitura deve ter um mediador que consiga incentivar os alunos a usufruir dos livros, e esse mediador é o bibliotecário. É ele quem irá compreender as necessidades do usuário, quais informações ele busca e que tipo de livro o atrai. A fim de que a leitura seja estimulada, é preciso que o bibliotecário pratique ações que vão além da sua função técnica. Caldin (2003) coloca que "[...] em um mundo em constantes mudanças, globalizado, não cabem mais procedimentos ditos tradicionais. $\mathrm{O}$ bibliotecário tem de largar seu papel passivo, de mero processador técnico de livros e desempenhar um papel ativo: agente de mudanças sociais". O bibliotecário deve saber lidar tanto com a parte técnica e administrativa de sua função quanto com a disseminação e mediação da informação. Ainda há quem não perceba (ou entenda) a função mediadora e educativa do bibliotecário. Seu trabalho dentro das unidades de informação vai além da organização e administração do acervo, ele deve ter a habilidade e a capacidade de auxiliar na utilização das fontes de informação, além incentivar a leitura e a competência informacional dos usuários.

Becker e Grosch (2008) destacam o papel do bibliotecário como agente na formação de leitores, fomentando ações de leitura que se conectam com as práticas da competência informacional. Para que essas ações aconteçam com sucesso, é necessário que o bibliotecário conheça seu usuário, seu acervo, seu espaço e que recursos pode utilizar. No que diz respeito ao usuário, a IFLA (2005) diz que "[...] todos aqueles que trabalham na biblioteca da escola devem ter bom relacionamento com crianças, jovens e adultos". Através desse contato com o usuário é possível saber quais livros lhes interessam, quais não lhes interessam e quais gostaria de conhecer, mas não tem acesso. Becker e Grosch (2008, p.42) reforçam a importância da relação entre bibliotecário e usuário dizendo que o bibliotecário "[...] deve contar com uma boa comunicação com os estudantes, ser agradável, criativo, responsável, e principalmente, saber compreender as crianças e saber conquistálas." Conhecer o universo dos livros infantis, 
nesse caso, é primordial para a promoção da leitura dentro da biblioteca.

As Diretrizes da IFLA/ UNESCO para a biblioteca escolar (2005) instruem ainda que é função cultural da biblioteca escolar organizar eventos especiais no seu espaço, tais como: exposições, visitas de autores, dentre outras atividades que estimulem o interesse pela leitura e o amor pela literatura. As ações culturais dentro da biblioteca contribuem bastante no incentivo à leitura e são ideais para chamar a atenção do público infantil, já que possibilitam um conjunto de atividades variadas. O bibliotecário, como mediador de leitura, deve proporcionar um ambiente com atividades lúdicas, possibilitando a interação dos usuários com os livros com o intuito de aguçar a curiosidade no conteúdo que pode encontrar, cumprindo assim o objetivo da biblioteca de disseminar a informação e fomentar a leitura dos usuários.

\section{AÇÕES NO COLÉGIO PEDRO II}

O Colégio Pedro II é uma instituição pública federal de ensino básico, equiparada desde 2012 aos Institutos Federais (BRASIL, 2012) cuja missão é "[...] promover a educação de excelência, pública, gratuita e laica, por meio da indissociabilidade do ensino, da pesquisa e da extensão" (COLÉGIO PEDRO II, 2011). O campus Humaitá I foi fundado em 1985 no bairro de mesmo nome, localizado no Rio de Janeiro. Cerca de 460 alunos entre seis e 12 anos de idade estudam no campus que oferece vagas para dois turnos, por meio de sorteio para o Ensino Fundamental do $1^{\circ}$ ao $5^{\circ}$ ano.

A biblioteca do campus atende os alunos e possui em seu acervo livros de literatura infantil e juvenil, enciclopédias, revistas e gibis, além de um acervo voltado aos professores do segmento. Através da observação da frequência dos usuários e dos empréstimos que eram realizados, constatouse que muitos alunos vinham à biblioteca mas não encontravam livros do seu interesse. Alguns alunos não chegavam a entrar porque pensavam que no espaço só havia livros "velhos, chatos ou de criança". Consequentemente, a média de empréstimos realizados, tanto de livros quanto de gibis, começou a sofrer uma diminuição. Foi percebida então a demanda para atrair os alunos de volta à biblioteca, indicando livros e gibis interessantes, de gêneros variados.

A primeira atividade pensada foi o trocatroca de livros e gibis, onde os alunos poderiam trocar entre si e escolher itens que nunca haviam lido antes. Isso inspirou a criação de um sábado letivo na escola, onde as Coordenações de Literatura e Língua Portuguesa do campus se uniram à equipe da biblioteca para o desenvolvimento de atividades para incentivar o uso da biblioteca e estimular hábitos de leitura entres os alunos. O planejamento envolveu também os professores das turmas para eles pudessem encorajar os alunos a virem participar do evento, além do apoio da Direção Pedagógica da Direção Geral. Devido às atividades que foram propostas, o evento foi nomeado "Encontro Literário".

O Encontro Literário ${ }^{3}$ aconteceu em 18 de Junho de 2016 no campus Humaitá I e envolveu todos os estudantes do $1^{\circ}$ ao $5^{\circ}$ ano e seus responsáveis. Além do troca-troca de livros e gibis, a biblioteca expôs obras de vários gêneros literários de autores brasileiros, como Monteiro Lobato, Ricardo Azevedo, Ana Maria Machado, Eva Furnari, Ziraldo, dentre outros. Ainda na entrada, os pais e responsáveis eram convidados a escrever os títulos que marcaram suas infâncias e a colocar no varal de Memórias Bibliográficas $\mathrm{O}$ evento contou ainda com exposições de trabalhos dos alunos e livros das aulas de literatura, além da reprodução de curtas sobre leitura e literatura. Houve oficinas de marcadores de páginas, de poemas ilustrados e de ilustrações com um ilustrador convidado. Pela manhã, uma autora convidada fez um bate-papo com os alunos sobre poesia e, logo após, iniciou-se o Sarau de Poesia. Outro ponto alto do evento foi a contação de estórias com autores convidados. No final do evento, a participação de uma orquestra de violões encantou o público com a apresentação de músicas literárias que

\footnotetext{
3

https://www.cp2.g12.br/ultimas_publicacoes/220not\%C3\%ADcias2016/4908-humait\%C3\%A1-irealiza-encontro-liter\%C3\%A1rio-com-alunos,pais-e-respons\%C3\%A1veis.html
} 
remetiam ao universo infanto-juvenil. $\mathrm{O}$ sorteio de brindes aos alunos que participaram do troca-troca encerrou o evento.

Apesar de planejado em pouco tempo, não houve problema em relação aos convidados. A preocupação que havia em relação ao trocatroca de livros era a falta de livros, que foi sanado quando os próprios professores doaram algumas obras. Uma situação inesperada foi a quantidade de pais que aproveitaram a vinda ao colégio para doarem livros para a biblioteca. No mais, o evento foi considerado um grande sucesso do início ao fim.

\section{CONSIDERAÇÕES FINAIS}

É fundamental que a biblioteca escolar ultrapasse a velha ideia de ser apenas um depósito de livros no colégio. O bibliotecário e sua equipe devem explorar os recursos que ela possui para promover cada vez mais o uso do seu espaço, sem se agarrar à ideia de apenas emprestar livros aos alunos. Ela tem como função cultural organizar eventos e projetos de fomento à leitura e o Encontro Literário é um exemplo de evento, pois foi possível integrar atividades culturais como chamariz para o uso da biblioteca.

Os frutos do Encontro Literário começaram a ser colhidos logo na semana seguinte. Os alunos vieram em peso para a biblioteca procurar as obras que tinham visto ou ouvido falar no dia do evento. O resultado disso foi a alta frequência de alunos presentes na biblioteca e o aumento de empréstimos realizados. Se antes a média de empréstimos por dia era cerca de oito itens, depois do evento a média passou a ser de 22 . Logo, o número de empréstimos aumentou consideravelmente, além do número de alunos que passaram a frequentar a biblioteca como espaço de leitura e para outras atividades escolares. Com isso, foi possível perceber quais os títulos e gêneros que interessaram aos alunos e que antes não estavam tão em destaque. Essa ação permitiu que os alunos se aproximassem da biblioteca e se sentissem à vontade para explorar as obras de literatura, despertando a curiosidade para novas obras.

Acredito que o desenvolvimento de projetos de fomento à leitura na escola necessita do engajamento da biblioteca. É nela que a criança será apresentada aos diversos gêneros literários e autores e, a partir disso, começará a se sentir estimulada a ler cada ver mais e sentir o gosto pela literatura. A biblioteca escolar é uma fonte rica para o desenvolvimento de atividades culturais e deve ser usada sempre que possível para projetos com vistas ao estímulo da leitura. No que diz respeito ao primeiro segmento do Ensino Fundamental, creio que o evento e os resultados obtidos sugerem a abertura de novos projetos de fomento à leitura para $o$ futuro.

\section{REFERÊNCIAS}

BECKER, Caroline da Rosa Ferreira; GROSCH, Maria Selma. A formação do leitor através das bibliotecas: o letramento e a ciência da informação como pressupostos. Revista Brasileira de Biblioteconomia e Documentação, Nova Série, São Paulo, v. 4, n. 1, p.35-45, jan./jun. $2008 . \quad$ Disponível em: <https://rbbd.febab.org.br/rbbd/article/view/5 9>. Acesso em: 16 set. 2016.

BRASIL. Lei $\mathrm{n}^{\circ} \mathbf{1 2 . 6 7 7}$, de 25 de junho de 2012. Dispõe sobre a criação de cargos efetivos, cargos de direção e funções gratificadas no âmbito do Ministério da Educação, destinados às instituições federais de ensino e dá outras providências. Brasília, DF, 25 jun. 2012. Disponível em: <http://www.planalto.gov.

br/ccivil_03/_ato2011-

2014/2012/lei/L12677.htm>. Acesso em: 14 dez. 2015.

CALDIN, Clarice Fortkamp. A função social da leitura na literatura infantil. Encontros Bibli: Revista Eletrônica de Biblioteconomia e Ciência da Informação. Florianópolis, n.15, $2003 . \quad$ Disponível em: <https://periodicos.ufsc.br/index.php/eb/articl e/view/15182924.2003v8n15p47/5235> Acesso em: 15 set. 2016.

COLÉGIO PEDRO II. Missão, visão e valores. Rio de Janeiro, 2011. Disponível em: 
<http://www.cp2.g12. br/cpii/missao.html . Acesso em: 20 ago. 2016.

COLÉGIO PEDRO II. Humaitá I realiza encontro literário com alunos, pais e responsáveis. Rio de Janeiro, 2016. Disponível em: < https://www.cp2.g12.br/ultimas_publicacoes/ 220-not\%C3\%ADcias2016/4908humait\%C3\%A1-i-realiza-encontroliter\%C3\%A1rio-com-alunos,-pais-erespons\%C3\%A1veis.html>. Acesso em: 18 ago. 2016.

CÔRTE, Adelaide Ramos e; BANDEIRA, Suelena Pinto. Biblioteca escolar. Brasília, DF: Briquet de Lemos, 2011.

IFLA， FEDERAÇÃO INTERNACIONAL DE ASSOCIAÇÕES DE BIBLIOTECÁRIOS E INSTITUIÇÕES. Diretrizes da IFLA/UNESCO para a biblioteca escolar. Tradução Neusa Dias de Macedo. São Paulo: IFLA, 2005. Disponível em: <http://www.ifla.org/files/assets/schoollibraries-resource-centers/publications/schoollibrary-guidelines/school-library-guidelinespt_br.pdf>. Acesso em: 15 set. 2016. $\begin{array}{lrr}\text { IFLA. } & \text { FEDERAÇÃO } & \text { INTERNACIONAL } \\ \text { DE ASSOCIAÇÕES DE BIBLIOTECÁRIOS } \\ \text { E }\end{array}$ IFLA/UNESCO para biblioteca escolar. Tradução Neusa Dias de Macedo. São Paulo: IFLA, 2002. Disponível em: < http://www.rbal.com.pt/Documentos\%20RB AL\%20pdf/Manifesto\%20Unesco\%20para\%2 0Bibliotecas\%20Escolares.pdf $>$. Acesso em: 16 set. 2016.

IFLA. INTERNATIONAL FEDERATION OF LIBRARY ASSOCIATIONS; UNESCO. School library manifesto. The Hague: IFLA, 1999. Disponível em: < http://archive.ifla.org/VII/s11/pubs/schoolma nif.htm>. Acesso em: 16 set. 2016.

IFLA. INTERNATIONAL FEDERATION OF LIBRARY ASSOCIATIONS; UNESCO. School library guidelines. IFLA, 2000. Disponível em: < http://archive.ifla.org/VII/s11/pubs/sguide02. pdf >. Acesso em: 15 set. 2016.

MACEDO, Neusa Dias de (Org.). Biblioteca escolar brasileira em debate: da memória profissional a um forum virtual. São Paulo: SENAC/ Conselho Regional de Biblioteconomia 8a Região, 2005. 